\title{
Lay perceptions of mental toughness: Understanding conceptual similarities and differences between lay and sporting contexts
}

\author{
Sarah Sorensen · Aaron Jarden · Grant Schofield
}

\begin{abstract}
The predominant focus on sporting populations has limited our conceptual understanding of mental toughness in lay contexts. On the basis of its wider benefits beyond sports, we sought to understand the central and peripheral attributes of mental toughness from a layperson's perspective. To this end, we employed a prototype analysis which consisted of two studies. In Study 1, a list of attributes of mental toughness was generated. In Study 2, these attributes were ranked for their centrality to mental toughness. Study 1 was an open-format questionnaire, where 138 laypeople generated a final list of 75 attributes of mental toughness. The most frequently mentioned attributes were self-belief, determination, perseverance, resilience and focus, which largely supported important attributes identified by athletes in existing mental toughness literature. Study 2 surveyed 136 laypeople, who identified mental strength, overcomes obstacles, achieves/operates under pressure, determination and resilience/recovery as the most central attributes to mental toughness. Although determination and resilience aligned with existing sporting accounts of mental toughness, the remaining attributes reflect differences in perception of mental toughness between sporting and lay contexts. Examination of peripherallyrated attributes provides insights into mental toughness as an enduring form of suffering. Overall, determination and resilience emerged as frequently mentioned, as well as highly central, and, as such, represent the foundation for a universal (i.e., not context-specific) understanding of mental toughness.
\end{abstract}

Keywords: mental toughness, prototype analysis, layperson, concept, definition

\section{Introduction}

Although sport has been a predominant focus, empirical research suggests that the benefits of mental toughness extend to a variety of non-sporting populations (Crust, 2007; Gerber et al., 2012; Gerber, Brand et al., 2013; Gerber, Kalak et al., 2013; Gucciardi \& Jones, 2012; Gucciardi, Hanton, Gordon, Mallett, \& Temby, 2015; St. Clair-Thompson, Bugler, Robinson, Clough, McGeown \& Perry, 2015). However, work that has been done across non-sporting fields has been done so from theoretical and expert perspectives, without knowledge of how laypeople understand the concept. The present study thus aims to realign knowledge towards lay or nonsporting populations to improve empirical and practical utility of mental toughness in lay contexts. 
Table 1a. Qualitatively-generated attributes of mental toughness in sporting populations

\begin{tabular}{|c|c|c|}
\hline Source & Method & Attributes \\
\hline $\begin{array}{l}\text { Jones, Hanton, \& } \\
\text { Connaughton } \\
(2002)\end{array}$ & $\begin{array}{l}\text { Interviews with } \\
\text { international performers }(n \\
=10) \text { from mixed } \\
\text { disciplines of sport. } \\
\text { Participants generated } \\
\text { attributes of mental } \\
\text { toughness and then rank- } \\
\text { ordered their importance. }\end{array}$ & $\begin{array}{l}\text { [In order of importance] Having an unshakable self-belief in one's ability to achieve goals; recovering from set- } \\
\text { backs and having increased determination to succeed; having an unshakable self-belief that one has qualities } \\
\text { and abilities greater than opponents; having an insatiable desire and internal motivation to succeed; being fully- } \\
\text { focused on the task in the face of competition-specific distractions; regaining psychological control following } \\
\text { unexpected events and uncontrollable events; overcoming physical and emotional pain while maintaining } \\
\text { technique and effort; accepting and coping with competition anxiety; thriving on the pressure of competition; } \\
\text { not being adversely affected by others' good and bad performances; remaining fully focused in the face of } \\
\text { personal life distractions; and the ability to switch a sport focus on and off. }\end{array}$ \\
\hline $\begin{array}{l}\text { Bull, Shambrook, } \\
\text { James \& Brooks } \\
\text { (2005) }\end{array}$ & $\begin{array}{l}\text { Interviews with } \\
\text { international cricket } \\
\text { players }(n=12) \text {. }\end{array}$ & $\begin{array}{l}\text { [Ordering not specified by authors] Parental influence, childhood background, exposure to foreign cricket, } \\
\text { opportunities to survive early setbacks, needing to "earn" success (environmental influences); independence, } \\
\text { self-reflection, competitiveness with self as well as others, resilient confidence (tough character); exploiting } \\
\text { learning opportunities, belief in quality preparation, self-set challenging targets, "never say die" mindset, "go } \\
\text { the extra mile" mindset, determination to make most of ability, belief in making the difference, thrive on } \\
\text { competition, willing to take risks (tough attitude); robust self-confidence (overcoming self-doubts, feeding-off } \\
\text { physical condition, maintaining self-focus) and thinking clearly (good decision-making, keeping perspective, } \\
\text { honest self-appraisal) (tough thinking). }\end{array}$ \\
\hline $\begin{array}{l}\text { Thelwell, } \\
\text { Weston, \& } \\
\text { Greenlees (2005) }\end{array}$ & $\begin{array}{l}\text { Interviews with } \\
\text { professional soccer players } \\
(n=6) \text { to generate } \\
\text { attributes of mental } \\
\text { toughness. Attributes were } \\
\text { then rank-ordered for their } \\
\text { importance to mental } \\
\text { toughness by an additional } \\
\text { sample of professional } \\
\text { soccer players }(n=43) \text {. }\end{array}$ & $\begin{array}{l}\text { [In order of importance] Having total self-belief at all times that you will achieve success; having the ability to } \\
\text { react to situations positively; having the ability to hang on and be calm under pressure; having the ability to } \\
\text { ignore distractions and remain focused; wanting the ball/wanting to be involved at all times; knowing what it } \\
\text { takes to grind yourself out of trouble; controlling emotions throughout performance; having a presence that } \\
\text { affects opponents; having everything outside of the game in control; and enjoying the pressure associated with } \\
\text { performance. }\end{array}$ \\
\hline
\end{tabular}




\section{Table 1b. Qualitatively-generated attributes of mental toughness in sporting populations}

Jones, Hanton, \& Interviews with athletes ( $n$ [In order of importance within each theme] Attitude/mindset: belief and focus; Training: using long-term goals

Connaughton $=8)$, coaches $(n=3)$ and sports psychologists $(n=$ 4). Participants generated attributes of mental

toughness and then rankordered their importance.

Gucciardi,

Gordon \& Interviews with Australian football coaches $(n=11)$.

Dimmock (2008) Participants generated attributes of mental toughness and then rankordered their importance.

Coulter, Mallett, Semi-structured interviews \& Gucciardi (2010) with soccer players $(n=6)$, coaches $(n=4)$ and parents $(n=5)$. Attribute importance identified by the number of participants that cited a particular theme.

Weinberg, Butt \& Interviews with head Culp (2011) coaches $(n=10)$ from a variety of sports.

[Ordering not specified by authors] Psychological skills (focus, confidence, knowledge and mental planning), motivation to succeed (motivation to work hard, persistence) and resilience (rebound from setbacks, handling and performing under pressure).

Driska,

Kamphoff \&

Armentrout

Semi-structured interviews with elite swimming coaches $(n=13)$ to confirm or modify the framework by Jones et al. (2007).

as the source of motivation, controlling the environment, pushing yourself to the limit; Competition: belief, staying focused, regulating performance, handling pressure, awareness and control of thoughts and feelings, controlling the environment; Post-competition: handling failure, handling success.

[In order of importance] Self-belief, work ethic (determination, perseverance, goals, meticulous preparation, time management, inspirational), personal values (honesty, pride in performance, accountability), selfmotivated (competitive desire, team success, vision), tough attitude (discipline, commitment, positivity, professionalism, sacrifices), concentration and focus, resilience, handling pressure (overriding negative thoughts), emotional intelligence (self-awareness), sport intelligence (team role responsibility, understanding the game), physical toughness.

[In order of importance] Winning mentality and desire, self-belief, physical toughness, work ethic, resilience, personal values, concentration and focus, performance awareness, sport intelligence, tough attitude, coping under pressure, competitive effort, risk-taking, emotional intelligence and control.

[Ordering not specified by authors] Attitude/mindset: belief, focus and coachability*; Training: using long-term goals as the source of motivation, controlling the environment, pushing yourself to the limit and retaining psychological control on poor training days*; Competition: belief, staying focused, regulating performance, handling pressure, awareness and control of thoughts and feelings ${ }^{* *}$, controlling the environment*; Postcompetition: handling failure, handling success.

*Proposed new sub-component,${ }^{* *}$ Did not receive support as a sub-component of mental toughness 
Table 1c. Qualitatively-generated attributes of mental toughness in sporting populations

Slack, Maynard, Semi-structured interviews [Ordering not specified by authors] Coping with pressure, resilience, robust self-belief, tough attitude, Butt \& Olusoga with Premier English achievement striving, strong work-ethic and sport intelligence. 
Because mental toughness has often been cited by researchers, coaches and athletes as an influential psychological factor in sporting success (Connaughton, Hanton, Jones, \& Wadey, 2008; Denison, 2007; Gould, Hodge, Peterson \& Petlichkoff, 1987; Holland, Woodcock, Cumming, \& Duda, 2010), sports psychologists and researchers have collected sizeable literatures pertaining to the conceptualisation, measurement and development of mental toughness. From these efforts, a plethora of attributes has been generated by sportspeople to characterise mental toughness (see Table 1 above).

However, none of these conceptualisations include perspectives of laypeople, which is particularly important considering that "different people explain mental toughness differently depending on their personal experience and interactions within their own social world" (Fawcett, 2011, p. 9). Because experiences of athletes and academics are likely to differ from those of laypeople, it is important that a comparison between these perspectives be made.

In particular, a between-context comparison is useful for a number of reasons. First, researchers need to ensure that "mental toughness" means the same thing when examining mental toughness in non-sporting contexts. Specifically, Fehr and Russell (1991) suggest lay perspectives are important for "freeing researchers from hidden assumptions and confusion" (1991, p. 436). As mental toughness is typically measured through self-report scales that are developed from theoretical or sporting-based conceptualisations, it is important for researchers to understand how these tools correspond to participants' ideas of the concept. Second, as the meaning of mental toughness is likely to be contextually bound (Bull et al., 2005; Fawcett, 2011; Madrigal, Hamill, \& Gill, 2013), lay theories may highlight previously overlooked components of mental toughness (Harasymchuk \& Fehr, 2013). Finally, understanding lay perceptions of mental toughness may contribute to promoting further recognition and understanding of the benefits that can be attained by mental toughness beyond sporting and achievement-related contexts.

To this end, we chose to employ a prototype analysis (Rosch, 1975) based on its usefulness for elucidating lay perceptions of "fuzzy" psychological phenomena elsewhere (e.g., love and commitment, Fehr, 1988; respect in close relationships, Frei \& Shaver, 2002; wellbeing, Hone, Schofield, \& Jarden, 2016; forgiveness, Kearns \& Fincham, 2004; and infidelity, Weiser, Lalasz, Weigel, \& Evans, 2014). A prototype perspective suggests that phenomena are comprised of numerous attributes that are organised in a hierarchical, rather than linear, fashion according to their centrality (or importance) to the phenomenon (Rosch, 1975). Based on their "proximity," the presence or absence of these attributes renders given cases as more or less typical of the phenomenon. For example, an animal is more likely to be classified as a bird if it contains prototypical features of a bird (e.g., clearly visible feathers, flying), such as a sparrow, than a case that does not contain these central features, such as a penguin (Kearns \& Fincham, 2004).

The prototype analysis is employed here in two parts. At the outset, a first group of participants are asked to freely generate typical attributes of mental toughness (Study 1). These attributes are then collected into a list so that a second group of participants can rank them for their centrality or importance to mental toughness (Study 2). Subsequent findings are discussed for their relevance to current and future directions in mental toughness research.

\section{Study 1: Generation of mental toughness attributes}

The purpose of Study 1 was to encourage participants to generate attributes of mental toughness using a free-response format. This approach to collecting mental toughness attributes aligned with previous prototype analyses and was beneficial for attaining a cross-section of opinions from a large sample size. 


\subsection{Method}

\subsubsection{Participants}

One hundred and thirty eight laypeople participated in the current research. Due to an accidental omission of demographic questions from the original questionnaire, demographic information was collected retrospectively from participants at the same time that study findings were communicated. Fifty-one (37\%) participants responded to the demographic questionnaire. These respondents consisted of females (57\%) and males (43\%), who ranged in age between 18 and 64+ years, with the biggest age groups being 50-64 years old (35\%) and 35-49 years old (33\%). Most participants were European/New Zealand European (92\%), with remaining ethnicities being Māori (2\%), Indian (2\%) and other (4\%). Participants worked across a range of industries in entry and managerial-level positions.

\subsubsection{Procedure}

Lay participants from various community, occupational and vocational groups, as well as friends and family, were invited to participate in the first stage of research in July 2015. Where possible, the invitation included presentation of the research aims and data collection in person. Due to time or location restrictions, some participants requested that study materials to be sent via email and returned at their convenience.

Once participants had read the information sheet and signed the consent form, the questionnaire invited participants to freely produce all features associated with mental toughness, according to the following instructions (adapted from Fehr \& Russell, 1984, Study 6):

This is a study on the attributes that people think of when they think of the word mental toughness in everyday situations. For example, if you were asked to list the attributes of a person experiencing fear, you might write possible danger occurs, attention is focused on the threat, heart beats wildly, the person runs as fast as they can. In the current study, we are not interested in attributes of fear but in attributes of mental toughness in everyday situations. Imagine that you are explaining the word mental toughness to someone who has no experience of mental toughness. Include the obvious. However, try not to just freeassociate. We're interested in what is common to instances of mental toughness. Remember that these attributes can be positive or negative.

These instructions were followed by a statement to re-clarify the question and prompt participants:

What, in your opinion, are the key attributes of mental toughness? Please list as many as you can below.

Participants were provided with 15 blank lines to enter their responses, and were encouraged to take as much time as needed to generate as many attributes of mental toughness as possible. Once participants had completed and submitted the questionnaire, snowball sampling was encouraged by asking participants if they were affiliated with other community or occupational groups who may appreciate the opportunity to participate in this research. This process was repeated until a sufficient sample size was obtained. 
Table 2. Frequency and mean centrality ratings of mental toughness features

Table 2a. Attributes sorted by Part 1 frequencies*

\begin{tabular}{|c|c|c|c|c|}
\hline \multirow[t]{2}{*}{ Attributes } & \multicolumn{2}{|c|}{ *Part 1} & \multicolumn{2}{|c|}{ Part 2} \\
\hline & Frequency & $\%$ & MCR & SD \\
\hline $\begin{array}{l}\text { Self-belief/confidence/sense of } \\
\text { competence }\end{array}$ & 54 & $31 \%$ & 5.42 & 1.19 \\
\hline Grit/perseverance & 53 & $30 \%$ & 5.59 & 1.33 \\
\hline Determination & 50 & $30 \%$ & 5.95 & 1.06 \\
\hline Focus/concentrate & 48 & $29 \%$ & 5.57 & 1.32 \\
\hline Resilience/recovery & 47 & $30 \%$ & 5.90 & 1.09 \\
\hline $\begin{array}{l}\text { Social } \\
\text { relationships/openness/receiving }\end{array}$ & & & & \\
\hline help & 44 & $22 \%$ & 4.64 & 1.69 \\
\hline Rational/analytical & 42 & $20 \%$ & 5.00 & 1.60 \\
\hline Calm and in control & 41 & $22 \%$ & 5.08 & 1.38 \\
\hline Purpose/goal focused & 33 & $20 \%$ & 5.50 & 1.34 \\
\hline Good decision maker & 33 & $15 \%$ & 4.31 & 1.26 \\
\hline $\begin{array}{l}\text { Absorb/cope/deal with stress and } \\
\text { pressure }\end{array}$ & 30 & $18 \%$ & 5.78 & 1.27 \\
\hline Optimism/positive expectations & 30 & $20 \%$ & 5.08 & 1.43 \\
\hline $\begin{array}{l}\text { Emotional } \\
\text { stability/strength/intelligence }\end{array}$ & 29 & $17 \%$ & 5.31 & 1.42 \\
\hline $\begin{array}{l}\text { Accept failure/negative situation a } \\
\text { part of life }\end{array}$ & 28 & $12 \%$ & 5.13 & 1.62 \\
\hline Stubborn & 25 & $14 \%$ & 4.72 & 1.64 \\
\hline Desire/driven/motivated & 24 & $14 \%$ & 5.61 & 1.29 \\
\hline Self-discipline ${ }^{1}$ & 24 & $14 \%$ & - & - \\
\hline Stand up for oneself/assertiveness & 23 & $12 \%$ & 5.52 & 1.23 \\
\hline Achieve/operate under pressure & 22 & $13 \%$ & 6.04 & 1.11 \\
\hline
\end{tabular}

Table 2b. Attributes sorted by Part 2 Mean Centrality Ratings (MCR)*

\begin{tabular}{|c|c|c|c|c|}
\hline \multirow{2}{*}{ Attributes } & \multicolumn{2}{|c|}{ Part 1} & \multicolumn{2}{|c|}{ *Part 2} \\
\hline & Frequency & $\%$ & MCR & SD \\
\hline Mental strength & 8 & $4 \%$ & 6.20 & 1.01 \\
\hline Overcomes obstacles & 14 & $9 \%$ & 6.05 & 1.09 \\
\hline Achieve/operate under pressure & 22 & $13 \%$ & 6.04 & 1.11 \\
\hline Determination & 50 & $30 \%$ & 5.95 & 1.06 \\
\hline Resilience/recovery & 47 & $30 \%$ & 5.9 & 1.09 \\
\hline $\begin{array}{l}\text { Absorb/cope/deal with stress and } \\
\text { pressure }\end{array}$ & 30 & $18 \%$ & 5.78 & 1.27 \\
\hline Taking responsibility & 5 & $4 \%$ & 5.78 & 1.30 \\
\hline Able to take criticism & 4 & $3 \%$ & 5.75 & 1.29 \\
\hline Commitment & 4 & $3 \%$ & 5.67 & 1.13 \\
\hline $\begin{array}{l}\text { Not feel inferior/not being } \\
\text { undermined }\end{array}$ & 5 & $4 \%$ & 5.66 & 1.26 \\
\hline Independence & 13 & $8 \%$ & 5.64 & 1.25 \\
\hline Desire/driven/motivated & 24 & $14 \%$ & 5.61 & 1.29 \\
\hline Reflection and growth/learning & 15 & $9 \%$ & 5.60 & 1.38 \\
\hline Grit/perseverance & 53 & $30 \%$ & 5.59 & 1.33 \\
\hline Put things in perspective & 15 & $10 \%$ & 5.59 & 1.26 \\
\hline Focus/concentrate & 48 & $29 \%$ & 5.57 & 1.32 \\
\hline Adaptable & 10 & $7 \%$ & 5.57 & 1.42 \\
\hline Stand up for oneself/assertiveness & 23 & $12 \%$ & 5.52 & 1.23 \\
\hline Purpose/goal focused & 33 & $20 \%$ & 5.50 & 1.34 \\
\hline Trust/respect yourself & 6 & $4 \%$ & 5.45 & 1.34 \\
\hline Strength - general & 15 & $8 \%$ & 5.44 & 1.32 \\
\hline $\begin{array}{l}\text { Self-belief/confidence/sense of } \\
\text { competence }\end{array}$ & 54 & $31 \%$ & 5.42 & 1.19 \\
\hline
\end{tabular}


Table 2a. Attributes sorted by Part 1 frequencies*

\begin{tabular}{|c|c|c|c|c|}
\hline \multirow{2}{*}{ Attributes } & \multicolumn{2}{|c|}{ *Part 1} & \multicolumn{2}{|c|}{ Part 2} \\
\hline & Frequency & $\%$ & MCR & SD \\
\hline Self-awareness & 22 & $12 \%$ & 5.08 & 1.44 \\
\hline Compartmentalise/dissociate & 18 & $12 \%$ & 5.23 & 1.30 \\
\hline Positive emotions (happy) & 17 & $9 \%$ & 4.22 & 1.43 \\
\hline Problem-solving ability & 16 & $11 \%$ & 5.39 & 1.24 \\
\hline One step at a time & 16 & $9 \%$ & 5.18 & 1.19 \\
\hline History and experience & 16 & $11 \%$ & 4.64 & 1.50 \\
\hline Reflection and growth/learning & 15 & $9 \%$ & 5.6 & 1.38 \\
\hline Put things in perspective & 15 & $10 \%$ & 5.59 & 1.26 \\
\hline Strength - general & 15 & $8 \%$ & 5.44 & 1.32 \\
\hline Resistant to influence & 15 & $8 \%$ & 4.97 & 1.41 \\
\hline Overcomes obstacles & 14 & $9 \%$ & 6.05 & 1.09 \\
\hline Courage & 14 & $8 \%$ & 5.23 & 1.21 \\
\hline Independence & 13 & $8 \%$ & 5.64 & 1.25 \\
\hline Clear thinking & 12 & $9 \%$ & 5.26 & 1.20 \\
\hline Proactive & 12 & $9 \%$ & 5.21 & 1.35 \\
\hline Open-minded/no prior judgements & 12 & $8 \%$ & 4.93 & 1.50 \\
\hline Effective interpersonal skills & 12 & $6 \%$ & 4.78 & 1.42 \\
\hline Empathy/compassion/kindness & 12 & $7 \%$ & 4.4 & 1.34 \\
\hline Wellbeing & 11 & $7 \%$ & 4.19 & 1.49 \\
\hline Adaptable & 10 & $7 \%$ & 5.57 & 1.42 \\
\hline Be prepared & 10 & $7 \%$ & 5.05 & 1.40 \\
\hline Knowledgeable & 10 & $7 \%$ & 4.83 & 1.24 \\
\hline Patience and tolerance & 10 & $6 \%$ & 4.62 & 1.42 \\
\hline $\begin{array}{l}\text { Thought control/independence from } \\
\text { thought }\end{array}$ & 9 & $4 \%$ & 5.21 & 1.33 \\
\hline Honesty/trustworthiness & 9 & $5 \%$ & 4.73 & 1.38 \\
\hline
\end{tabular}

Table 2b. Attributes sorted by Part 2 Mean Centrality Ratings (MCR)*

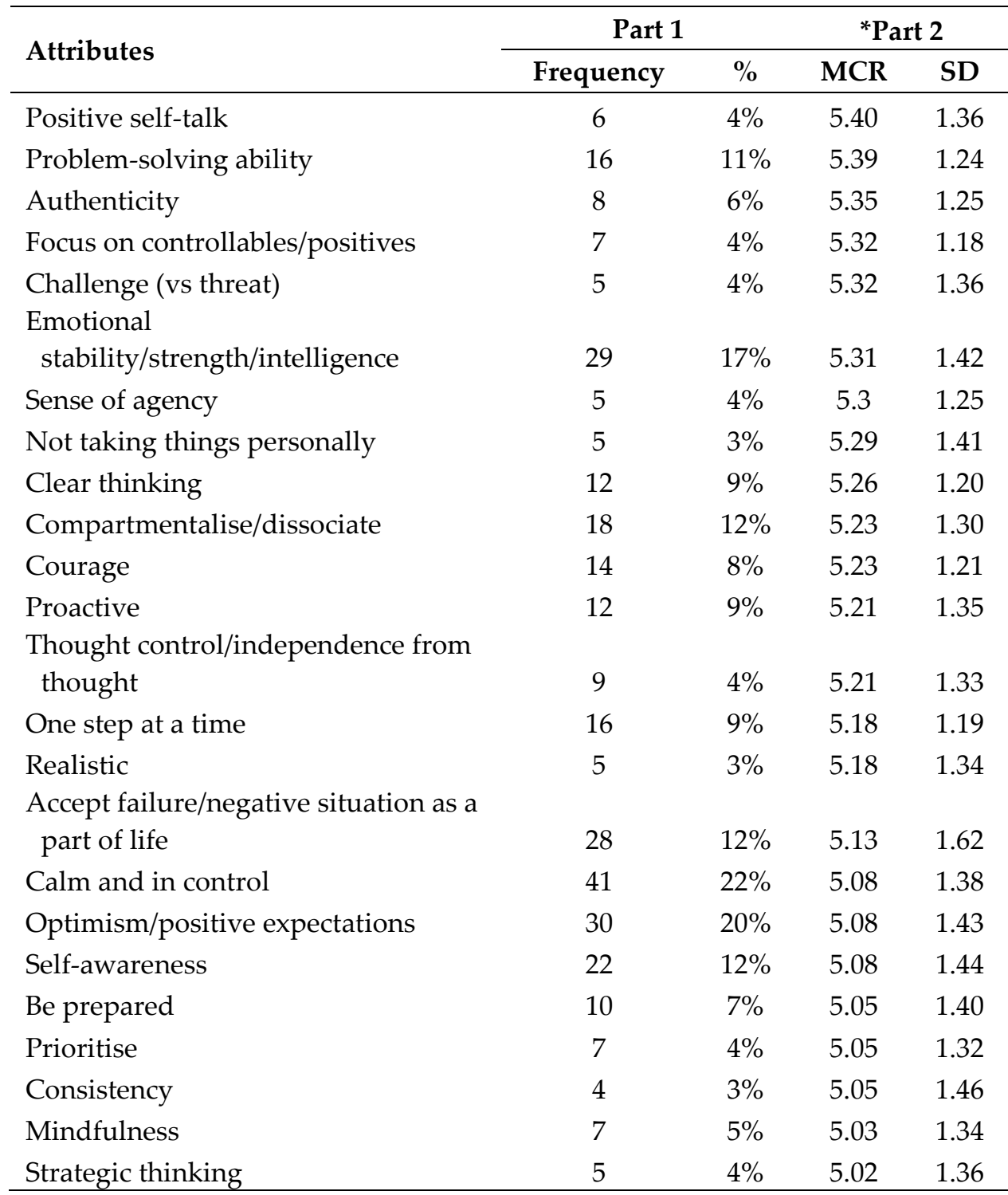


Table 2a. Attributes sorted by Part 1 frequencies*

\begin{tabular}{lcccc}
\hline \multirow{2}{*}{ Attributes } & \multicolumn{2}{c}{${ }^{*}$ Part 1 } & \multicolumn{3}{c}{ Part 2 } \\
\cline { 2 - 5 } & Frequency & $\%$ & MCR & SD \\
\hline Mental strength & 8 & $4 \%$ & 6.2 & 1.01 \\
Authenticity & 8 & $6 \%$ & 5.35 & 1.25 \\
Clear moral code & 8 & $4 \%$ & 5 & 1.34 \\
Planning & 8 & $6 \%$ & 4.99 & 1.41 \\
Humour & 8 & $5 \%$ & 4.68 & 1.45 \\
Focus on controllables/positives & 7 & $4 \%$ & 5.32 & 1.18 \\
Prioritise & 7 & $4 \%$ & 5.05 & 1.32 \\
Mindfulness & 7 & $5 \%$ & 5.03 & 1.34 \\
Altruism & 7 & $4 \%$ & 4.55 & 1.31 \\
Trust/respect yourself & 6 & $4 \%$ & 5.45 & 1.34 \\
Positive self-talk & 6 & $4 \%$ & 5.4 & 1.36 \\
Leadership/taking control & 6 & $4 \%$ & 4.71 & 1.42 \\
Quick thinking & 6 & $3 \%$ & 4.55 & 1.33 \\
Emotional openness & 6 & $4 \%$ & 4.14 & 1.45 \\
Mental recovery/escape & 6 & $3 \%$ & 4.04 & 1.59 \\
Selfishness & 5 & $4 \%$ & 3.37 & 1.50 \\
Religious faith & 5 & $3 \%$ & 5.29 & 1.41 \\
Taking responsibility & 5 & $3 \%$ & 5.18 & 1.34 \\
Not feel inferior/not being & 5 & $4 \%$ & 5.02 & 1.36 \\
$\quad$ undermined & 5 & 4.86 & 1.48 \\
Challenge (vs threat) & 5 & 5.78 & 1.30 \\
Sense of agency & 5 & 5.66 & 1.26 \\
Not taking things personally & 5 & 5.32 & 1.36 \\
Realistic & 5 & & & \\
Strategic thinking & 5 & 4.3 & 1.25 \\
Flexible & 5 & $4 \%$ & & \\
\hline
\end{tabular}

Table 2b. Attributes sorted by Part 2 Mean Centrality Ratings (MCR)*

\begin{tabular}{|c|c|c|c|c|}
\hline \multirow{2}{*}{ Attributes } & \multicolumn{2}{|c|}{ Part 1} & \multicolumn{2}{|c|}{ *Part 2} \\
\hline & Frequency & $\%$ & MCR & SD \\
\hline Rational/analytical & 42 & $20 \%$ & 5 & 1.60 \\
\hline Clear moral code & 8 & $4 \%$ & 5 & 1.34 \\
\hline Planning & 8 & $6 \%$ & 4.99 & 1.41 \\
\hline Resistant to influence & 15 & $8 \%$ & 4.97 & 1.41 \\
\hline Open-minded/no prior judgements & 12 & $8 \%$ & 4.93 & 1.50 \\
\hline Flexible & 5 & $4 \%$ & 4.86 & 1.48 \\
\hline Knowledgeable & 10 & $7 \%$ & 4.83 & 1.24 \\
\hline Effective interpersonal skills & 12 & $6 \%$ & 4.78 & 1.42 \\
\hline Honesty/trustworthiness & 9 & $5 \%$ & 4.73 & 1.38 \\
\hline Stubborn & 25 & $14 \%$ & 4.72 & 1.64 \\
\hline Leadership/taking control & 6 & $4 \%$ & 4.71 & 1.42 \\
\hline Humour & 8 & $5 \%$ & 4.68 & 1.45 \\
\hline $\begin{array}{l}\text { Social } \\
\text { relationships/openness/receiving }\end{array}$ & & & & \\
\hline help & 44 & $22 \%$ & 4.64 & 1.69 \\
\hline History and experience & 16 & $11 \%$ & 4.64 & 1.50 \\
\hline Gratitude & 5 & $3 \%$ & 4.64 & 1.43 \\
\hline Patience and tolerance & 10 & $6 \%$ & 4.62 & 1.42 \\
\hline Altruism & 7 & $4 \%$ & 4.55 & 1.31 \\
\hline Quick thinking & 6 & $3 \%$ & 4.55 & 1.33 \\
\hline Empathy/compassion/kindness & 12 & $7 \%$ & 4.4 & 1.34 \\
\hline Good decision maker & 33 & $15 \%$ & 4.31 & 1.26 \\
\hline Humble & 5 & $3 \%$ & 4.27 & 1.51 \\
\hline Tough because no choice/necessity & 4 & $3 \%$ & 4.24 & 1.69 \\
\hline Positive emotions (happy) & 17 & $9 \%$ & 4.22 & 1.43 \\
\hline
\end{tabular}


Table 2a. Attributes sorted by Part 1 frequencies*

\begin{tabular}{lcccc}
\hline \multirow{2}{*}{ Attributes } & \multicolumn{2}{c}{${ }^{*}$ Part 1 } & \multicolumn{2}{c}{ Part 2 } \\
\cline { 2 - 5 } & Frequency & \% & MCR & SD \\
\hline Gratitude & 5 & $3 \%$ & 4.64 & 1.43 \\
Humble & 5 & $3 \%$ & 4.27 & 1.51 \\
Able to take criticism & 4 & $3 \%$ & 5.75 & 1.29 \\
Commitment & 4 & $3 \%$ & 5.67 & 1.13 \\
Consistency & 4 & $3 \%$ & 5.05 & 1.46 \\
Tough because no choice/necessity & 4 & $3 \%$ & 4.24 & 1.69 \\
\hline
\end{tabular}

Table 2b. Attributes sorted by Part 2 Mean Centrality Ratings (MCR)*

\begin{tabular}{lccccc}
\hline \multirow{2}{*}{ Attributes } & \multicolumn{2}{c}{ Part 1 } & \multicolumn{3}{c}{${ }^{*}$ Part 2 } \\
\cline { 2 - 5 } & Frequency & \% & MCR & SD \\
\hline Wellbeing & 11 & $7 \%$ & 4.19 & 1.49 \\
Mental recovery/escape & 6 & $3 \%$ & 4.04 & 1.59 \\
Selfishness & 6 & $4 \%$ & 3.37 & 1.50 \\
Religious faith & 6 & $4 \%$ & 2.65 & 1.50 \\
Self-discipline $^{1}$ & 24 & $14 \%$ & - & - \\
\hline
\end{tabular}

\footnotetext{
${ }^{1}$ Due to an administrative error, the attribute of self-discipline was omitted from importance rankings in Study 2 . As discipline appears in the list of attributes presented by Gucciardi et al. (2008) and may be related to the attribute of work ethic (Coulter et al., 2010; Gucciardi et al., 2008; Slack et al., 2013), it is speculated that self-discipline may have been considered a central attribute of mental toughness. Future research may elucidate these inconclusive findings.
} 


\subsection{Results and discussion}

For the purposes of data manageability, the first and second authors first allocated raw entries into one of five categories: social, motivational, emotional, psychological or other. Once data had been organised into these five categories, in line with the procedure used by Fehr (1988), the next step involved the extraction of linguistic units. Using this procedure, monolexic items (e.g., "determination") were first identified and extracted. Where phrases were used, judgements were made to determine whether the phrase referred to a single linguistic unit (e.g., "ability to stay focused on the job at hand" was coded as "focus") or split into multiple linguistic units (e.g., "to be brave and determined to achieve goals when situations are hard" was split into "bravery" and "determination"). The 138 participants generated an average of 8.14 linguistic units each, yielding a total of 1,124 units from this analysis.

Upon extraction, linguistic units were allocated to existing groups if they were similar in meaning or if they formed different grammatical versions of the same word. If linguistic units did not fall into existing attribute categories based on this criteria, new attribute categories were created. Any ambiguous words or phrases were left until the end of the analysis and placed in an "unsure" category if their meaning could not be ascertained by the researchers. A total number of 44 units were placed in the "unsure" category (e.g., "inner self") and subsequently excluded from further analysis.

In the process of grouping linguistic units, words or phrases that were similar yet slightly different (e.g., "objective thinking" and "rational") were first allocated to separate attribute categories to retain conceptual richness. Initially, the linguistic units formed 101 feature categories. However, to reduce participant burden in Study 2, similar categories were subsequently combined (e.g., "objective thinking" and "rational" were judged as similar enough to be combined into one category group), and categories mentioned by less than $2 \%$ of the sample were excluded from the final list of attributes. Subsequently, 75 final attribute categories were identified, which are displayed in Table $2 \mathrm{a}$ above.

As shown in Table $2 \mathrm{a}$ above, the most popular features were self-belief (mentioned by $31 \%$ of participants), followed by determination, perseverance, resilience (mentioned by $30 \%$ of participants), and focus (mentioned by $29 \%$ of participants). Based on what we already know about mental toughness in sporting contexts (see Table 1 above), the frequent occurrence of these attributes is unsurprising. However, lay participants more frequently identified social attributes of mental toughness than their sporting counterparts. These social attributes included social openness and seeking out help from others (e.g., "the ability to talk through an issue out loud"), as well as resisting unfavourable social pressures (e.g., "not getting influenced by people around you") and asserting one's opinions or needs when necessary (e.g., "being able to stand up for something despite your own hardships"). Positive virtues oriented towards others, such as empathy, compassion and kindness, were also included, which builds on the attribute of personal values (e.g., honesty and integrity) identified by Gucciardi et al. (2008) and Coulter et al. (2010).

\section{Study 2: Centrality ratings of mental toughness features}

The purpose of Study 2 was to gain centrality or importance ratings of the attributes generated in the previous study. The methodology in this study aligns with steps taken by previous researchers to organise attributes in order of their importance to mental toughness (e.g., Gucciardi et al., 2008; Jones et al., 2002; Jones et al., 2007; Thelwell et al., 2005). With comparison between previous and current centrality ratings, therefore, findings from this study will indicate 
differences or similarities between sporting and lay perceptions of "typical" characteristics of mental toughness.

\subsection{Method}

\subsubsection{Participants}

One hundred and thirty six laypeople participated in the current research. As with Study 1 above, due to an accidental omission of demographic questions from the original questionnaire, demographic information was collected retrospectively from participants at the same time that study findings were communicated. Thirty-one participants $(24 \%)$ responded to the demographic questions. These participants consisted of females $(82 \%)$ and males $(18 \%)$ who ranged from 18-64 years old, with the largest groups being 25-34 year olds (36\%) and 50-64 year olds (33\%). The majority were European/New Zealand European (88\%), with other ethnicities being Māori (3\%) and other (9\%). Participants worked across a range of industries in entry and managerial-level positions. Overall, participant demographics in Study 2 were similar to those in Study 1.

\subsubsection{Procedure}

Similar participant recruitment and data collection procedures to Study 1 were followed in Study 2 to obtain a new sample. Once participants had read the information sheet and signed the consent form, the questionnaire (see Appendix) provided participants with the following instructions:

In a previous study, we asked people to tell us their views of mental toughness. Specifically, we asked them to "list the characteristics or attributes of mental toughness that come to mind." Below are some of the responses we got. We now want to find out how important each attribute is to mental toughness. In other words...

Typically, a mentally tough person is someone who is...

The questionnaire was divided into five sections, following the higher-level categories developed in Study 1: social aspects, motivational aspects, emotional aspects, psychological aspects and other. Under each heading, participants were provided with further instructions:

Please read through the entire list and then rate how typical each attribute is by circling a number between 1 (not at all typical) and 7 (extremely typical).

The features allocated to each category were then presented to participants in each section, sorted by alphabetical order. Features were reworded to suit the questionnaire instructions, and simplified, if necessary, to enhance comprehension (e.g., "altruism" was reworded to "willing to make personal sacrifices for others").

\subsection{Results and discussion}

Mean Centrality Ratings (MCR) for the 75 attributes are presented in Table $2 b$ above. The most centrally-rated attributes of mental toughness include mental strength, overcomes obstacles, achieve/operate under pressure, determination, and resilience/recovery. Two indices were computed to establish the reliability of these mean centrality ratings. First, the intra-class correlation coefficient (ICC; equivalent to the average of all possible split-half correlations of the 136 judges with respect to the 75 attributes) reached significance $(\mathrm{ICC}=.941 ; p<.01$ ) thus 
indicating excellent inter-rater agreement. Second, based on a flipped data matrix that treats the 75 features as cases and the 136 judges as items, the internal consistency of the dataset was exceptionally high $(\alpha=.95)$.

Significant agreement $(r=.31, p<.01)$ was found between the frequency percentages (Study 1 ) and centrality ratings (Study 2) of attributes. For instance, determination and resilience were both frequently mentioned and assigned high centrality ratings. However, although intercorrelations were significant overall, features such as self-belief, perseverance and focus were mentioned frequently but assigned relatively low centrality ratings. On the other hand, mental strength, overcomes obstacles and achieve/operate under pressure were mentioned relatively infrequently but assigned high centrality ratings.

Finally, we demarcated central from peripheral attributes of mental toughness by calculating a central median split of mean centrality ratings. On this basis, all attributes with a mean centrality rating above 5.08 were considered central $(n=41)$ and all attributes below $(n=33)$ were considered peripheral ${ }^{2}$. In particular, participants considered mental strength, overcomes obstacles, achieve operate under pressure, determination and resilience/recovery as central attributes of mental toughness. In comparison with existing knowledge, the high centrality ratings assigned to determination and resilience converge with findings by Bull et al. (2005), Coulter et al. (2010), Gucciardi et al., 2008, Jones et al. (2002), Slack et al., (2013) and Weinberg et al. (2001), and the remaining central attributes represent unique components of mental toughness. On the other hand, positive emotions (happy), wellbeing, emotional openness, mental recovery/escape, selfishness and religious faith were rated as peripheral or non-important attributes to mental toughness.

\section{Overall discussion}

Despite empirical investigations in non-sporting contexts (e.g., Gerber et al., 2012; Gerber, Brand et al., 2013; Gerber, Kalak et al., 2013; Gucciardi et al., 2015; St. Clair-Thompson et al., 2015), lay perceptions of mental toughness remain relatively unexplored. On this basis, the current research used a prototype analysis to understand lay perspectives of central and peripheral attributes of mental toughness. Findings from this analysis verify as well as expand existing knowledge in a number of ways and thus progress empirical and practical utility of mental toughness beyond sporting contexts.

First, in line with existing literature, mental toughness was construed using a wide variety of attributes $(n=75)$. As this number of attributes resembles the total number of attributes generated for other common everyday constructs (e.g., love and commitment, $n=68$ and 40 features respectively, Fehr, 1988; forgiveness, $n=78$ features, Kearns \& Fincham, 2004; infidelity, $n=95$ features, Weiser et al., 2014), findings suggest that mental toughness is a familiar term to laypeople.

As participants were also able to meaningfully and reliably distinguish between these attributes according to centrality, the current findings provided preliminary evidence of the prototypical nature or "internal structure" of mental toughness (Rosch, 1975). Although we did not test the impact of centrality on cognitions with respect to mental toughness (the second criteria for demonstrating prototypical organisation; Rosch, 1975), this preliminary evidence lends credence to reviewers who note the conceptual chaos inherent in linear lists of attributes (e.g., Andersen, 2011). Findings further highlight the necessity for current and future researchers

\footnotetext{
${ }^{2}$ We acknowledge, however, that the dichotomous nature of this approach somewhat conflicts with the continuous nature of feature centrality.
} 
to heed the hierarchical organisation of attributes to achieve a valid and organised evolution of understanding, measuring, and developing mental toughness.

Second, findings in the present study enabled a comparison between lay and sporting perceptions of the "internal structure" of mental toughness. For instance, determination and resilience are familiar attributes within existing conceptualisations, and, as such, future research may include resilience and determination as a viable avenue for understanding the universal (i.e., not context-specific) attributes and mechanisms underlying mental toughness. Notwithstanding these similarities, a number of differences between perspectives also exist. For example, although frequently mentioned, attributes central to sporting perspectives such as selfbelief and focus were rated as less important to mental toughness by laypeople. Instead, findings suggest that laypeople view mental strength as the most important attribute of mental toughness. Although not coherently documented, various researchers have used mental strength to describe qualities of emotional stability (Deutscher, Frick, \& Prinz, 2013), an ability to make hard decisions (Glozah, 2015), a strong "sense of self" that facilitates a capacity to deal with intimidating or difficult situations (such as domestic violence; Rose et al., 2010), focus, intelligence, the ability to learn, deep commitment, a positive outlook and an ability to resist feeling overwhelmed or discouraged (Stewart, 2009). As such, mental strength may be a higher-order attribute encompassing a collection of sub-attributes of mental toughness. An in-depth understanding of the nature of mental strength and its sub-components may provide fruitful avenues for "teasing out" various higher-order dimensions and mechanisms underlying mental toughness.

Particularly noteworthy was the relative prominence of outcomes in laypeople's perceptions of mental toughness, which included recovery/resilience as well as overcoming obstacles and being able to achieve/operate under pressure. With the exception of resilience, these outcomes are relatively absent from previous rankings of important attributes; however, they do appear in a number of existing definitions of mental toughness, such as overcoming obstacles (e.g., Gucciardi et al., 2008) and performance and goal attainment under stress (e.g., Coulter et al., 2010; Gucciardi et al., 2015; Hardy, Bell, \& Beattie, 2013; Loehr, 1994; Mahoney, Gucciardi, Mallett, \& Ntoumantis, 2014). Although resilience, overcoming obstacles and being able to achieve/operate under pressure may take on different forms in everyday situations, their centrality may highlight the necessity of positive outcomes for conceptualising mental toughness; that is, if attributes previously associated with mental toughness (see Table 1 above) occur in the absence of these central outcomes, are they still indicative of mental toughness? With the exception of the Cricket Mental Toughness Inventory (CTMI, Gucciardi \& Gordon, 2009) which includes the subscale of resilience, this finding also highlights a challenge for applying current scales to non-sporting populations that solely rely on internal states or processes as indicators of mental toughness without concurrent attention to outcomes (e.g., Australian Football Mental Toughness Inventory, Gucciardi, Gordon \& Dimmock, 2009a; Mental Toughness Questionnaire 48, Clough, Earle, \& Sewell, 2002; Mental Toughness Scale, Madrigal et al., 2013; Psychological Performance Inventory, Loehr, 1986; Sports Mental Toughness Questionnaire, Sheard, Golby \& van Wersch, 2009). This observation is further extended to interventions that target development of less central attributes (e.g., coping, optimism and various psychological skills; Bell, Hardy, \& Beattie, 2013; Gucciardi, Gordon, \& Dimmock, 2009b; Parkes \& Mallett, 2011; Sheard \& Golby, 2006).

We also found that although frequently-mentioned attributes were generally rated as more central, this trend was relatively absent from the social dimension of mental toughness. In particular, social relationships/openness/receiving help (i.e., a willingness to ask for help or openness to receiving help from friends and family) was the sixth most frequently mentioned attribute but was subsequently rated as peripheral to mental toughness. From what we know, 
social support does play a role in mentally tough outcomes (Smith, Wolfe-Clarke, \& Bryan, 2016) and is widely cited as a source of mental toughness development (e.g., Bull et al., 2005; Connaughton, Wadey, Hanton, \& Jones, 2008). However, although participants may have recognised the role of social support as an attribute, the act of asking or receiving help may not have been interpreted as typical to mental toughness.

These findings, along with other peripherally rated attributes (such as emotional openness, positive emotions - or happiness - wellbeing, mental recovery/escape and religiosity), may represent an enduring form of suffering, which, according to Morse (2001), is an emotionless state where emotions are suppressed or tolerated in order to enable an individual to function adequately and "come to grips" with a situation. This state is particularly reminiscent of peripherally-rated behaviours (such as little emotion, maintenance of control: that is, does not escape or attribute control over outcomes to external religious figures) that discourages rather than invites social consolation. Although speculative, it is plausible that enduring suffering is also characteristic of the highly central attribute of mental strength and facilitates central outcomes (i.e., recovering from setbacks, overcoming obstacles and being able to achieve/operate (i.e., function) under pressure).

In all, the present study informed current theories of mental toughness by conceptualising mental toughness as a prototypically organised construct from a layperson's viewpoint. In doing so, findings supported some already well-established dimensions of mental toughness (i.e., resilience and determination), but also highlighted some conceptual differences. These differences include the overarching theme of mental strength, as well as the emphasis on outcomes as defining attributes of mental toughness. From examination of the social and peripheral attributes of mental toughness, current findings also highlighted the potential for mental toughness to be characteristic of enduring versus emotional suffering in stressful situations. Future research would do well to investigate and heed these universal and contextdependent "inner structures" of mental toughness to facilitate a valid and sophisticated conceptual, empirical and practical understanding of mental toughness.

\section{Limitations}

First, as demographic information was retrospectively collected, we could only estimate sample demographics based on a proportion of participant demographics. As such, we are unsure how demographics may have influenced the responses gained in the current research, and, although unlikely, we were not able to guarantee that participants were not involved in elite sports as well. Second, contrary to previous interview methods that enabled further probing of responses (e.g., Coulter et al., 2010; Gucciardi et al., 2008; Jones et al., 2002; Thelwell et al., 2005), the present method used open-response questionnaires to attain attributes of mental toughness. Although this approach was useful for obtaining a range of different opinions across a large sample size and aligned with previous prototype analyses, open-ended questionnaires prevented us from elaborating meaning in some responses. Finally, we were able to demonstrate preliminary evidence for the prototypical organisation of mental toughness, however, without testing the effect of centrality on cognitions regarding mental toughness, we were unable to conclusively argue its prototypical organisation. Thus, testing the cognitive effects of attribute centrality is an important consideration for future research.

\section{Authors}

Sarah Sorensen

Auckland University of Technology 
Aaron Jarden

Auckland University of Technology

aaron.jarden@aut.ac.nz

Grant Schofield

Auckland University of Technology

\section{Publishing Timeline}

Received 3 August 2016

Accepted 9 September 2016

Published 14 October 2016

\section{References}

Andersen, M. B. (2011). Who's mental, who's tough and who's both? In D. Gucciardi \& S. Gordon (Eds.), Mental toughness in sport: Developments in theory and research (pp. 69-88). London, England: Taylor \& Francis.

Bell, J. J., Hardy, L., \& Beattie, S. (2013). Enhancing mental toughness and performance under pressure in elite young cricketers: A 2-year longitudinal intervention. Sport, Exercise, and Performance Psychology, 2(4), 281. http://dx.doi.org/10.1037/a0033129

Bull, S. J., Shambrook, C. J., James, W., \& Brooks, J. E. (2005). Towards an understanding of mental toughness in elite English cricketers. Journal of Applied Sport Psychology, 17(3), 209-227. http://dx.doi.org/10.1080/10413200591010085

Clough, P. J., Earle, K., \& Sewell, D. (2002). Mental toughness: The concept and its measurement. In I. Cockerill (Ed.), Solutions in sport psychology (pp. 32-43). London, England: Thomson.

Connaughton, D., Hanton, S., Jones, G., \& Wadey, R. (2008). Mental toughness research: Key issues in this area. International Journal of Sport Psychology, 39, 192-204.

Connaughton, D., Wadey, R., Hanton, S., \& Jones, G. (2008). The development and maintenance of mental toughness: Perceptions of elite performers. Journal of Sports Sciences, 26(1), 83-95. http://dx.doi.org/10.1080/02640410701310958

Coulter, T. J., Mallett, C. J., \& Gucciardi, D. F. (2010). Understanding mental toughness in Australian soccer: Perceptions of players, parents, and coaches. Journal of Sports Sciences, 28(7), 699-716. http://dx.doi.org/10.1080/02640411003734085

Crust, L. (2007). Mental toughness in sport: A review. International Journal of Sport and Exercise Psychology, 5(3), 270-290. http://dx.doi.org/10.1080/1612197X.2007.9671836

Denison, J. (2007). Social theory for coaches: A Foucauldian reading of one athlete's poor performance. International Journal of Sports Science and Coaching, 2(4), 369-383. http://dx.doi.org/10.1260/174795407783359777

Deutscher, C., Frick, B., \& Prinz, J. (2013). Performance under pressure: Estimating the returns to mental strength in professional basketball. European Sport Management Quarterly, 13(2), 216-231. http://dx.doi.org/10.1080/16184742.2012.742122

Driska, A. P., Kamphoff, C., \& Mork Armentrout, S. (2012). Elite swimming coaches' perceptions of mental toughness. Sport Psychologist, 26(2), 186-206. http://dx.doi.org/10.1123/tsp.26.2.186

Fawcett, T. (2011). Mental toughness: A phenomenological perspective. In D. Gucciardi \& S. Gordon (Eds.), Mental toughness in sport: Developments in theory and research (pp. 69-88). London, England: Taylor \& Francis.

Fehr, B. (1988). Prototype analysis of the concepts of love and commitment. Interpersonal Relations and Group Processes, 55(4), 557-579. http://dx.doi.org/10.1037/0022-3514.55.4.557

Fehr, L., \& Russell, J. A. (1984). Concept of emotion viewed from a prototype perspective. Journal of Experimental Psychology: General, 113, 464-486. http://dx.doi.org/10.1037/0096-3445.113.3.464

Fehr, B., \& Russell, J. A. (1991). The concept of love viewed from a prototype perspective. Journal of Personality and Social Psychology, 60(3), 425. http://dx.doi.org/10.1037/0022-3514.60.3.425 
Frei, J. R., \& Shaver, P. R. (2002). Respect in close relationships: Prototype definition, self-report assessment, and initial correlates. Personal Relationships, 9(2), 121-139. http://dx.doi.org/10.1111/1475$\underline{6811.00008}$

Gerber, M., Kalak, N., Lemola, S., Clough, P. J., Pühse, U., Elliot, C.,... \& Brand, S. (2012). Adolescents' exercise and physical activity are associated with mental toughness. Mental Health and Physical Activity, 5, 35-42. http://dx.doi.org/10.1016/j.mhpa.2012.02.004

Gerber, M., Brand, S., Feldmeth, A. K., Lang, C., Elliot, C., Holsboer-Trachsler, E., \& Pühse, U. (2013). Adolescents with high mental toughness adapt better to perceived stress: A longitudinal study with Swiss vocational students. Personality and Individual Differences, 54(7), 808-814. http://dx.doi.org/10.1016/j.paid.2012.12.003

Gerber, M., Kalak, N., Lemola, S., Clough, P., Perry, J. L., Pühse, U.,... Brand, S. (2013). Are adolescents with higher mental toughness more resilient against stress? Stress and Health, 29, 164-171. http://dx.doi.org/10.1002/smi.2447

Glozah, F. N. (2015). Exploring Ghanaian adolescents' meaning of health and wellbeing: A psychosocial perspective. International Journal of Qualitative Studies on Health and Well-being, 10. http://dx.doi.org/10.3402/qhw.v10.26370

Gould, D., Hodge, K., Peterson, K., \& Petlichkoff, L. (1987). Psychological foundations of coaching: Similarities and differences among intercollegiate wrestling coaches. The Sport Psychologist, 1, 293308. http://dx.doi.org/10.1123/tsp.1.4.293

Gucciardi, D. F., \& Gordon, S. (2009). Development and preliminary validation of the Cricket Mental Toughness Inventory (CMTI). Journal of Sports Sciences, 27, 1293-1310. http://dx.doi.org/10.1080/02640410903242306

Gucciardi, D. F., Gordon, S., \& Dimmock, J. A. (2008). Towards an understanding of mental toughness in Australian football. Journal of Applied Sport Psychology, 20, 261-281. http://dx.doi.org/10.1080/10413200801998556

Gucciardi, D. F., Gordon, S., \& Dimmock, J. A. (2009a). Development and preliminary validation of a mental toughness inventory for Australian football. Psychology of Sport and Exercise, 10, 201-209. http://dx.doi.org/10.1016/j.psychsport.2008.07.011

Gucciardi, D. F., Gordon, S., \& Dimmock, J. A. (2009b). Evaluation of a Mental Toughness Training Program for Youth-Aged Australian Footballers: I. A Quantitative Analysis. Journal of Applied Sport Psychology, 21, 307-323. http://dx.doi.org/10.1080/10413200903026066

Gucciardi, D. F., Hanton, S., Gordon, S., Mallett, C. J., \& Temby, P. (2015). The concept of mental toughness: Tests of dimensionality, nomological network, and traitness. Journal of Personality, 83(1), 26-44. http://dx.doi.org/10.1111/jopy.12079

Gucciardi, D. F., \& Jones, M. I. (2012). Beyond optimal performance: Mental toughness profiles and developmental success in adolescent cricketers. Journal of Sport and Exercise Psychology, 34(1), 16. http://dx.doi.org/10.1123/jsep.34.1.16

Harasymchuk, C., \& Fehr, B. (2013). A prototype analysis of relational boredom. Journal of Social and Personal Relationships, 30(5), 627-646. http://dx.doi.org/10.1177/0265407512464483

Hardy, L., Bell, J., \& Beattie, S. (2014). A neuropsychological model of mentally tough behavior. Journal of Personality, 82(1), 69-81. http://dx.doi.org/10.1111/jopy.12034

Holland, M. J., Woodcock, C., Cumming, J., \& Duda, J. L. (2010). Mental qualities and employed mental techniques of young elite team sport athletes. Journal of Clinical Sport Psychology, 4, 19-38. http://dx.doi.org/10.1123/jcsp.4.1.19

Hone, L., Schofield, G., \& Jarden, A. (2016). Conceptualizations of wellbeing: Insights from a prototype analysis on New Zealand workers. New Zealand Journal of Human Resource Management, 12(2), 97-118.

Jones, G., Hanton, S., \& Connaughton, D. (2002). What is this thing called mental toughness? An investigation of elite sport performers. Journal of Applied Sports Psychology, 14, 205-218. http://dx.doi.org/10.1080/10413200290103509

Jones, G., Hanton, S., \& Connaughton, D. (2007). A framework of mental toughness in the world's best performers. The Sport Psychologist, 21, 243-264. http://dx.doi.org/10.1123/tsp.21.2.243 
Kearns, J. N., \& Fincham, F. D. (2004). A prototype analysis of forgiveness. Personality and Social Psychology Bulletin, 30(7), 838-855. http://dx.doi.org/10.1177/0146167204264237

Loehr, J. E. (1986). Athletic excellence: Mental toughness training for sports. New York, NY: Plume.

Loehr, J. E. (1994). The new toughness training for sports. New York, NY: Penguin Group.

Madrigal, L., Hamill, S., Gill, D. L. (2013). Mind over matter: The development of the Mental Toughness Scale (MTS). The Sport Psychologist, 27, 62-77. http://dx.doi.org/10.1123/tsp.27.1.62

Mahoney, J. W., Gucciardi, D. F., Mallett, C. J., \& Ntoumanis, N. (2014). Adolescent performers' perspectives on mental toughness and its development: The utility of the bioecological model. Sport Psychologist, 28(3), 233-244. http://dx.doi.org/10.1123/tsp.2013-0050

Morse, J. M. (2001). Towards a praxis theory of suffering. Advances in Nursing Science, 24(1), 47-59. http://dx.doi.org/10.1097/00012272-200109000-00007

Parkes, J. F., \& Mallett, C. J. (2011). Developing mental toughness: Attributional style retraining in rugby. The Sport Psychologist, 25, 269-287. http://dx.doi.org/10.1123/tsp.25.3.269

Rosch, E. (1975).Cognitive representations of semantic categories. Journal of Experimental Psychology: General, 104(3), 192-233. http://dx.doi.org/10.1037/0096-3445.104.3.192

Rose, L., Alhusen, J., Bhandari, S., Soeken, K., Marcantonio, K., Bullock, L., \& Sharps, P. (2010). Impact of intimate partner violence on pregnant women's mental health: Mental distress and mental strength. Issues in Mental Health Nursing, 31(2), 103-111. http://dx.doi.org/10.3109/01612840903254834

Sheard, M., Golby, J., \& van Wersch, A. (2009). Progress toward construct validation of the Sports Mental Toughness Questionnaire. European Journal of Psychological Assessments, 25, 186-193. http://dx.doi.org/10.1027/1015-5759.25.3.186

Slack, L. A., Maynard, I. W., Butt, J., \& Olusoa, P. (2013). Factors underpinning football officiating excellence: Perceptions of English Premier League referees. Journal of Applied Sport Psychology, 25, 298-315. http://dx.doi.org/10.1080/10413200.2012.726935

Smith, H. A., Wolfe-Clark, A. L., \& Bryan, C. J. (2016). An exploratory study of the mental toughness psychological skills profile psychometrics, and the mediating effect of social support sources on mental toughness and suicidal ideation among military police. Journal of Police and Criminal Psychology, 1-9. http://dx.doi.org/10.1007/s11896-016-9192-y

St. Clair-Thompson, H., Bugler, M., Robinson, J., Clough, P., McGeown, S. P., \& Perry, J. (2015). Mental toughness in education: Exploring relationships with attainment, attendance, behaviour and peer relationships. Educational Psychology, 35(7), 886-907. http://dx.doi.org/10.1080/01443410.2014.895294

Stewart, M. C. (2009). Constructing masculine and athletic identities: The case of college football players. Ann Arbor, MI: ProQuest.

Thelwell, R., Weston, N., \& Greenlees, I. (2005). Defining and understanding mental toughness within soccer. Journal of Applied Sport Psychology, 17(4), 326-332. http://dx.doi.org/10.1080/10413200500313636

Weinberg, R., Butt, J., \& Culp, B. (2011). Coaches' views of mental toughness and how it is built. International Journal of Sport and Exercise Psychology, 9, 156-172.

http://dx.doi.org/10.1080/1612197X.2011.567106

Weiser, D. A., Lalasz, C. B., Weigel, D. J., \& Evans, W. P. (2014). A prototype analysis of infidelity. Personal Relationships, 21(4), 655-675. http://dx.doi.org/10.1111/pere.12056 
Appendix

Questionnaire administered to participants in study 2

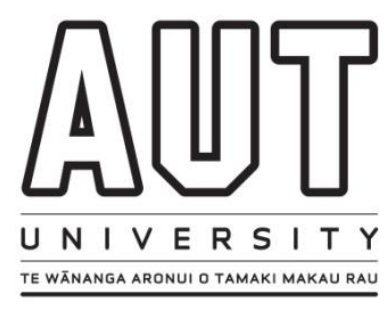

\section{Mental Toughness}

In a previous study, we asked people to tell us their views of mental toughness. Specifically, we asked them to "list the characteristics or attributes of mental toughness that come to mind." Below are some of the responses we got. We now want to find out how important each attribute is to mental toughness. In other words...

\section{Typically, a mentally tough person is someone who is...}

Part 1: Social aspects

Please read through the entire list and then rate how typical each attribute is by circling a number between 1 (not at all typical) and 7 (extremely typical).

\begin{tabular}{|c|c|c|c|c|c|c|c|}
\hline \multicolumn{3}{|c|}{ Not at all typical } & \multicolumn{3}{|c|}{ Sort of typical } & \multicolumn{2}{|c|}{ Extremely typical } \\
\hline A good leader & 1 & 2 & 3 & 4 & 5 & 6 & 7 \\
\hline $\begin{array}{l}\text { Able to accept } \\
\text { responsibility or } \\
\text { 'own it' }\end{array}$ & 1 & 2 & 3 & 4 & 5 & 6 & 7 \\
\hline $\begin{array}{l}\text { Able to take } \\
\text { criticism }\end{array}$ & 1 & 2 & 3 & 4 & 5 & 6 & 7 \\
\hline $\begin{array}{l}\text { Assertive } \\
\text { (stand up for } \\
\text { themselves) }\end{array}$ & 1 & 2 & 3 & 4 & 5 & 6 & 7 \\
\hline $\begin{array}{c}\text { Effective } \\
\text { communicators }\end{array}$ & 1 & 2 & 3 & 4 & 5 & 6 & 7 \\
\hline $\begin{array}{l}\text { Good at not } \\
\text { taking things } \\
\text { personally }\end{array}$ & 1 & 2 & 3 & 4 & 5 & 6 & 7 \\
\hline $\begin{array}{l}\text { Guided by a clear } \\
\text { moral code }\end{array}$ & 1 & 2 & 3 & 4 & 5 & 6 & 7 \\
\hline Humble & 1 & 2 & 3 & 4 & 5 & 6 & 7 \\
\hline
\end{tabular}




\begin{tabular}{|c|c|c|c|c|c|c|c|}
\hline \multicolumn{3}{|c|}{ Not at all typical } & \multicolumn{3}{|c|}{ Sort of typical } & \multicolumn{2}{|c|}{ Extremely typical } \\
\hline Independent & 1 & 2 & 3 & 4 & 5 & 6 & 7 \\
\hline $\begin{array}{c}\text { Just themselves } \\
\text { (authentic) }\end{array}$ & 1 & 2 & 3 & 4 & 5 & 6 & 7 \\
\hline $\begin{array}{c}\text { Kind and } \\
\text { compassionate }\end{array}$ & 1 & 2 & 3 & 4 & 5 & 6 & 7 \\
\hline $\begin{array}{l}\text { Not easily } \\
\text { intimidated or } \\
\text { undermined }\end{array}$ & 1 & 2 & 3 & 4 & 5 & 6 & 7 \\
\hline $\begin{array}{l}\text { Open to receiving } \\
\text { help / support }\end{array}$ & 1 & 2 & 3 & 4 & 5 & 6 & 7 \\
\hline $\begin{array}{c}\text { Resistant to } \\
\text { influence from } \\
\text { others }\end{array}$ & 1 & 2 & 3 & 4 & 5 & 6 & 7 \\
\hline Selfish & 1 & 2 & 3 & 4 & 5 & 6 & 7 \\
\hline Trustworthy & 1 & 2 & 3 & 4 & 5 & 6 & 7 \\
\hline $\begin{array}{l}\text { Willing to make } \\
\text { personal } \\
\text { sacrifices for } \\
\text { others }\end{array}$ & 1 & 2 & 3 & 4 & 5 & 6 & 7 \\
\hline
\end{tabular}

Part 2: Goals and Motivation

\section{Typically, a mentally tough person is someone who is...}

Please read through the entire list and then rate how typical each attribute is by circling a number between 1 (not at all typical) and 7 (extremely typical).

Not at all typical

Sort of typical

Extremely typical

\begin{tabular}{|c|c|c|c|c|c|c|c|}
\hline $\begin{array}{c}\text { Able to achieve or } \\
\text { operate under } \\
\text { pressure }\end{array}$ & 1 & 2 & 3 & 4 & 5 & 6 & 7 \\
\hline $\begin{array}{c}\text { Able to overcome } \\
\text { obstacles }\end{array}$ & 1 & 2 & 3 & 4 & 5 & 6 & 7 \\
\hline Committed & 1 & 2 & 3 & 4 & 5 & 6 & 7 \\
\hline
\end{tabular}




\begin{tabular}{|c|c|c|c|c|c|c|c|}
\hline \multicolumn{9}{c}{ Not at all typical } \\
\hline Confident & 1 & 2 & 3 & 4 & 5 & 6 & 7 \\
\hline Consistent & 1 & 2 & 3 & 4 & 5 & 6 & 7 \\
\hline $\begin{array}{c}\text { Determined } \\
\text { Focused }\end{array}$ & 1 & 2 & 3 & 4 & 5 & 6 & 7 \\
\hline $\begin{array}{c}\text { Goal or purpose } \\
\text { driven }\end{array}$ & 1 & 2 & 3 & 4 & 5 & 6 & 7 \\
\hline $\begin{array}{c}\text { Gritty } \\
\text { (perseveres) }\end{array}$ & 1 & 2 & 3 & 4 & 5 & 6 & 7 \\
\hline $\begin{array}{c}\text { Has a desire to } \\
\text { succeed }\end{array}$ & 1 & 2 & 3 & 4 & 5 & 6 & 7 \\
\hline $\begin{array}{c}\text { In control } \\
\text { tough because }\end{array}$ & 1 & 2 & 3 & 4 & 5 & 6 & 7 \\
\hline $\begin{array}{c}\text { Proactive } \\
\text { choice }\end{array}$ & 1 & 2 & 3 & 4 & 5 & 6 & 7 \\
\hline
\end{tabular}

Part 3: Emotions

\section{Typically, a mentally tough person is someone who is...}

Please read through the entire list and then rate how typical each attribute is by circling a number between 1 (not at all typical) and 7 (extremely typical).

Not at all typical

Sort of typical

Extremely typical

\begin{tabular}{|c|c|c|c|c|c|c|c|}
\hline $\begin{array}{c}\text { Able to deal with } \\
\text { stress and } \\
\text { pressure }\end{array}$ & 1 & 2 & 3 & 4 & 5 & 6 & 7 \\
\hline $\begin{array}{c}\text { Able to express } \\
\text { emotions }\end{array}$ & 1 & 2 & 3 & 4 & 5 & 6 & 7 \\
\hline $\begin{array}{c}\text { Able to see the } \\
\text { funny side of a } \\
\text { situation }\end{array}$ & 1 & 2 & 3 & 4 & 5 & 6 & 7 \\
\hline
\end{tabular}




\begin{tabular}{|c|c|c|c|c|c|c|c|}
\multicolumn{4}{|c}{ Not at all typical } & \multicolumn{1}{c|}{ Sort of typical } \\
\hline $\begin{array}{c}\text { Calm and in } \\
\text { control }\end{array}$ & 1 & 2 & 3 & 4 & 5 & 6 & 7 \\
\hline Courageous & 1 & 2 & 3 & 4 & 5 & 6 & 7 \\
\hline $\begin{array}{c}\text { Emotionally } \\
\text { stable / strong }\end{array}$ & 1 & 2 & 3 & 4 & 5 & 6 & 7 \\
\hline $\begin{array}{c}\text { Happy } \\
\text { Patient and } \\
\text { tolerant }\end{array}$ & 1 & 2 & 3 & 4 & 5 & 6 & 7 \\
\hline Resilient & 1 & 2 & 3 & 4 & 5 & 6 & 7 \\
\hline
\end{tabular}

Part 4: Psychological aspects

\section{Typically, a mentally tough person is someone who is...}

Please read through the entire list and then rate how typical each attribute is by circling a number between 1 (not at all typical) and 7 (extremely typical).

Not at all typical Sort of typical

Extremely typical

\begin{tabular}{|c|c|c|c|c|c|c|c|}
\hline A clear thinker & 1 & 2 & 3 & 4 & 5 & 6 & 7 \\
\hline A good planner & 1 & 2 & 3 & 4 & 5 & 6 & 7 \\
\hline $\begin{array}{c}\text { A good problem- } \\
\text { solver }\end{array}$ & 1 & 2 & 3 & 4 & 5 & 6 & 7 \\
\hline $\begin{array}{c}\text { A quick thinker } \\
\text { A rational thinker }\end{array}$ & 1 & 2 & 3 & 4 & 5 & 6 & 7 \\
\hline $\begin{array}{c}\text { A slow but good } \\
\text { decision-maker }\end{array}$ & 1 & 2 & 3 & 4 & 5 & 6 & 7 \\
\hline $\begin{array}{c}\text { A strategic } \\
\text { thinker }\end{array}$ & 1 & 2 & 3 & 4 & 5 & 6 & 6 \\
\hline
\end{tabular}


Not at all typical

Sort of typical

Extremely typical

\begin{tabular}{|c|c|c|c|c|c|c|c|}
\hline $\begin{array}{c}\text { Able to } \\
\text { compartmentalise } \\
\text { / detach } \\
\text { themselves }\end{array}$ & 1 & 2 & 3 & 4 & 5 & 6 & 7 \\
\hline $\begin{array}{l}\text { Able to control } \\
\text { their thoughts }\end{array}$ & 1 & 2 & 3 & 4 & 5 & 6 & 7 \\
\hline $\begin{array}{l}\text { Able to learn } \\
\text { from mistakes }\end{array}$ & 1 & 2 & 3 & 4 & 5 & 6 & 7 \\
\hline $\begin{array}{l}\text { Able to put } \\
\text { things in } \\
\text { perspective }\end{array}$ & 1 & 2 & 3 & 4 & 5 & 6 & 7 \\
\hline $\begin{array}{c}\text { Able to take it } \\
\text { one step at a time }\end{array}$ & 1 & 2 & 3 & 4 & 5 & 6 & 7 \\
\hline $\begin{array}{l}\text { Able to trust / } \\
\text { respect } \\
\text { themselves }\end{array}$ & 1 & 2 & 3 & 4 & 5 & 6 & 7 \\
\hline $\begin{array}{c}\text { Accepting of } \\
\text { failure / negative } \\
\text { situations as part } \\
\text { of life }\end{array}$ & 1 & 2 & 3 & 4 & 5 & 6 & 7 \\
\hline Adaptable & 1 & 2 & 3 & 4 & 5 & 6 & 7 \\
\hline Flexible & 1 & 2 & 3 & 4 & 5 & 6 & 7 \\
\hline $\begin{array}{l}\text { Good at positive } \\
\text { self-talk (e.g., } \\
\text { "you can do } \\
\text { this") }\end{array}$ & 1 & 2 & 3 & 4 & 5 & 6 & 7 \\
\hline $\begin{array}{l}\text { Good at } \\
\text { prioritising }\end{array}$ & 1 & 2 & 3 & 4 & 5 & 6 & 7 \\
\hline Grateful & 1 & 2 & 3 & 4 & 5 & 6 & 7 \\
\hline Knowledgeable & 1 & 2 & 3 & 4 & 5 & 6 & 7 \\
\hline $\begin{array}{c}\text { Likely to enjoy } \\
\text { pressure or 'the } \\
\text { challenge' }\end{array}$ & 1 & 2 & 3 & 4 & 5 & 6 & 7 \\
\hline $\begin{array}{l}\text { Likely to focus on } \\
\text { controllable }\end{array}$ & 1 & 2 & 3 & 4 & 5 & 6 & 7 \\
\hline
\end{tabular}




\begin{tabular}{|c|c|c|c|c|c|c|c|}
\hline \multicolumn{3}{|c|}{ Not at all typical } & \multicolumn{3}{|c|}{ Sort of typical } & \multicolumn{2}{|c|}{ Extremely typical } \\
\hline $\begin{array}{l}\text { /positive aspects } \\
\text { of a situation }\end{array}$ & & & & & & & \\
\hline $\begin{array}{l}\text { Likely to take } \\
\text { time out / escape } \\
\text { from the situation }\end{array}$ & 1 & 2 & 3 & 4 & 5 & 6 & 7 \\
\hline Mentally strong & 1 & 2 & 3 & 4 & 5 & 6 & 7 \\
\hline Mindful & 1 & 2 & 3 & 4 & 5 & 6 & 7 \\
\hline Open-minded & 1 & 2 & 3 & 4 & 5 & 6 & 7 \\
\hline $\begin{array}{c}\text { Positive (e.g., } \\
\text { optimistic) }\end{array}$ & 1 & 2 & 3 & 4 & 5 & 6 & 7 \\
\hline Prepared & 1 & 2 & 3 & 4 & 5 & 6 & 7 \\
\hline Realistic & 1 & 2 & 3 & 4 & 5 & 6 & 7 \\
\hline Religious & 1 & 2 & 3 & 4 & 5 & 6 & 7 \\
\hline Self-aware & 1 & 2 & 3 & 4 & 5 & 6 & 7 \\
\hline Stubborn & 1 & 2 & 3 & 4 & 5 & 6 & 7 \\
\hline
\end{tabular}

Part 5: Other

\section{Typically, a mentally tough person is someone who is...}

Please read through the entire list and then rate how typical each attribute is by circling a number between 1 (not at all typical) and 7 (extremely typical).

Not at all typical

Sort of typical

Extremely typical

\begin{tabular}{|c|c|c|c|c|c|c|c|}
\hline $\begin{array}{c}\text { A strong } \\
\text { character }\end{array}$ & 1 & 2 & 3 & 4 & 5 & 6 & 7 \\
\hline Experienced & 1 & 2 & 3 & 4 & 5 & 6 & 7 \\
\hline
\end{tabular}




\begin{tabular}{|c|c|c|c|c|c|c|c|}
\hline \multicolumn{3}{c}{ Not at all typical } & \multicolumn{3}{c}{ Sort of typical } & \multicolumn{2}{c}{ Extremely typical } \\
\hline Healthy & 1 & 2 & 3 & 4 & 5 & 6 & 7 \\
\hline
\end{tabular}

